\title{
Now on Display: Lessons Learned from Building a Small Exhibits Program ${ }^{1}$
}

\section{By Jolie Braun}

\begin{abstract}
In 2012, the Duke University Medical Center Library and Archives (DUMCL\&A) began the process of establishing a small exhibits program. This article examines the challenges of learning how to create exhibits, identifying and selecting materials for display, and documenting policies and procedures with the goal of demonstrating that even small organizations with limited resources, funding, or experience can create compelling, attractive exhibits.
\end{abstract}

\section{Introduction}

In 2011, institutional restructuring resulted in the Duke University Medical Center Library and Archives (DUMCL\&A) acquiring its own exhibit space for the first time. The History of Medicine Collections, previously part of the DUMCL\&A, moved to the Rubenstein Library, the special collections unit on the main Duke University campus. The DUMCL\&A was fortunate to inherit four high-quality, secure exhibit cases in an environmentally controlled climate and plenty of supplies. Lacking, however, was designated staff with exhibition expertise, a wealth of artifacts and rare books to display, or a clear plan. This article discusses how staff learned to build and manage a small, successful exhibits program. Specifically, it addresses the challenges of learning how to create exhibits, identifying and selecting materials for display, and documenting policies and procedures.

During the first year the DUMCL\&A had custody of the cases, it had no plan for creating displays. One or two staff members selected books and materials from the library's collection to display, rotating them periodically, but without a set schedule. In 2012, a committee comprised of two archivists and three librarians formed to plan an exhibit celebrating the library's 80 th anniversary at the request of the associate dean for Library Services. While intended as a one-time event, the attention and positive feedback received from administration, faculty, and staff provided the impetus to launch a program.

At the outset, the committee agreed that exhibits should be a means of furthering the DUMCL\&A's educational mission and fostering a greater understanding of Duke Health history. ${ }^{2}$ The archivists involved also advocated for using exhibits to showcase not just items from the library's collection, but unique archival materials as well. The committee made decisions related to establishing the program, including the annual number of exhibits and their topics. Although no budget was designated, funds were allotted to purchase supplies and print signage. ${ }^{3}$ 
Adjacent to a major medical center, the DUMCL\&A serves Duke Health faculty, staff, and students in the School of Medicine, School of Nursing, allied health programs, and graduate programs in the basic medical sciences, as well as the Duke University Hospital and Duke Health system. While this context provided a clearly intended audience-the Duke Health community-medical faculty and students have demanding workloads and hectic schedules, and they can be difficult to reach. Furthermore, the DUMCL\&A had 25 full-time employees (three of whom were archives staff). As an organization with a small, busy staff, committee members knew they had to think carefully about how much time and effort they could devote to exhibits and recognized that they needed to be strategic about how to make them relevant to their constituency.

\section{Learning about Exhibit Planning and Preparation}

While some of the committee members had previously worked on exhibits, none had completed coursework or training in exhibit planning and design. This is unsurprising, as classes on the topic within library and information science programs are rare. ${ }^{4}$ Jessica Lacher-Feldman observed that "archivists often learn on the job, with limited tools, skills, and support. Filling an exhibit case is often an afterthought, something that needs to be done, but is approached without any planning, vision, or skill." ${ }^{5}$ Because a wealth of writing exists about exhibit standards, best practices, and methods-information that may not necessarily be acquired through the experience of curating and installing exhibits - the committee decided to familiarize itself with some of the literature to have a better sense of how to establish the program. While this approach required significant time at the outset, ultimately it enabled more efficient, knowledgeable, and confident decisions and improved the quality of exhibits.

The amount of material on the topic was daunting, but one aspect of the project was reassuring: committee members did not need to become exhibit experts. Instead, they simply needed to have a basic knowledge of how to plan and execute engaging, attractive exhibits, determine standards, and create documentation. More specifically, this meant establishing the program's goals and process, as well as learning about writing exhibit labels, displaying materials, and preservation guidelines. This would require research, but it did not need to be exhaustive. As regular work duties and projects with more urgent deadlines took precedence, the committee gave itself six months to complete this process.

Committee members consulted a handful of books on exhibit preparation within libraries, archives, and museums. Most notably, Jessica Lacher-Feldman's Exhibits in Archives and Special Collections Libraries proved to be an invaluable resource, providing clear guidelines for each step of the process. ${ }^{6}$ It was particularly useful for its guidance in layout and design and recommendations for crafting a narrative. Beverly Serrell's Exhibit Labels: An Interpretive Approach was essential to learning how to write labels. Serrell's emphasis on the visitor's experience helped the committee prioritize succinctness; understand how to draw the visitor's eye back to each item with concrete, visual information; and write labels that can stand alone (as visitors may not follow the path intended or read every label). ${ }^{7}$ The book also provided specific recommendations for other aspects 
of label content, including tone, language, and style, as well as typographic and format standards, such as preferred fonts and text size.

The committee also reviewed articles about exhibit planning and preparation. ${ }^{8}$ Shawn Aubitz and Gail F. Stern's "Developing Archival Exhibitions” and Jennifer Brannock's "Creating an Exhibit in Special Collections and Using It to Promote Collections and Educate Users" provided accessible, step-by-step overviews for those new to the process. . Stephen Bitgood's "Practical Guidelines for Developing Interpretive Labels" described how to develop a story, organize information, and write exhibit text. ${ }^{10}$ Bitgood's "The ABCs of Label Design” expanded upon the potential issues inherent in capturing visitors' attention and strategies for creating effective, readable labels. ${ }^{11}$ The National Library of Scotland and the University of Edinburgh's "Exhibiting the Written Word" was immensely useful for its discussion of the challenges and advantages of displaying documents. ${ }^{12}$

Another important step was reviewing the exhibit policies and procedures of other institutions, which many libraries and archives have available on their websites. ${ }^{13}$ These documents provided current, real-world examples of goals and criteria, security and preservation recommendations, technical guidelines, and approaches to publicity and marketing that informed the DUMCL\&A's policies and procedures. While most were created by larger organizations, many had relevant, translatable concepts. For example, although the DUMCL\&A did not have preservation staff to review materials or oversee installation, the committee still wanted to include guidelines for selecting, displaying, and installing items to prevent damage and help ensure their longevity. By consulting general resources on this topic and reviewing relevant information in the policies and procedures of other institutions, the committee was able to incorporate basic preservation best practices into its documentation. ${ }^{14}$

Last, the committee sought out relevant professional development opportunities. Most committee members took an exhibits workshop (jointly offered by the Society of North Carolina Archivists and the North Carolina Preservation Consortium) that provided an overview of the process from concept to installation. One member also took a matting workshop (offered by the North Carolina Preservation Consortium) and learned techniques for making window mats that he was then able to use in exhibit preparation. Because local organizations offered these opportunities, the costs were low. ${ }^{15}$

\section{Selecting Exhibit Topics and Identifying Materials}

After the first few exhibits, committee members realized that an exhibit topic could radically impact the time and effort needed for identifying and selecting materials, a crucial lesson for a small organization lacking the options of a large institution. Jennifer Brannock recommended conducting preliminary research to ensure that a sufficient amount of relevant and appropriate materials exist before committing to a topic. ${ }^{16}$ In his writing on the National Archives exhibition program, Albert H. Leisinger Jr. noted that even at an institution with a wealth of materials, staff must first do a quick survey 
to identify possible exhibit items as some topics are sparsely documented or the available items may not be suitable for display. ${ }^{17}$ The exhibit committee learned that a topic that closely aligned with collection strengths, had materials clearly associated with it, and/ or had been documented or written about worked best. Such a topic made the process of identifying and selecting items easier and faster, allowed for greater flexibility, and resulted in a more dynamic-looking display. An exhibit on the history of hyperbaric medicine at Duke - an interesting but somewhat esoteric subject-required more original research, had fewer options for display, and took longer to execute than an exhibit about Duke's Physician Assistant Program, which could be researched more easily and was associated with multiple collections. The committee members' readings and experiences helped them realize that the first step in creating a successful exhibit was choosing a strong, relevant topic that afforded many options for the cases and allowed for the telling of a compelling story.

At first, the committee was uncertain about how to identify and select materials for the exhibits, a common problem for small libraries and archives with modest collections. ${ }^{18}$ As of 2015, the archives had 11,000 linear feet of material, a limited number of artifacts, and no rare books. ${ }^{19}$ Furthermore, because the archives' mission is to document and preserve the history of the Medical Center from its founding in 1930 to the present, the bulk of the collection comprised twentieth-century documents. ${ }^{20}$ Though the collection contained hidden gems worth showcasing, how to create varied, interesting exhibits with the archives' holdings was not immediately clear.

These limitations required strategic thinking and a critical assessment of the collections. The archivists on the exhibits committee realized they needed to go beyond the materials most often consulted during daily work - meeting minutes, departmental histories, administrative correspondence, budgetary and planning documents-which were typically accessed for the information they contained rather than for visual appeal. In doing so, they discovered that the concern about using documents had obscured their potential. Nancy Allyn et al. asserted that "although documents are commonly perceived as unattractive, many have extraordinary visual appeal and can be the sole subject of an exhibition. ${ }^{21}$ By reviewing finding aids and collections, the archivists discovered many possibilities within the document holdings: correspondence with illustrated letterheads, advertisements and publicity materials, patents, drawings, sketches, maps, floor plans, and charts.

Yet the archivists also realized that they should not disregard documents that may not be beautiful but tell an important part of a story. In "Exhibiting the Written Word," the Library of Scotland and the University of Edinburgh spoke to this idea:

... an emphasis on showing beautiful but exceptional artefacts can lead visitors away from understanding the nature of a library or archive collection and from engaging with the important texts it contains. There is the risk that this approach limits the kind of exhibitions that can be mounted-it would be 
difficult to tell all the complex stories of the world's words by relying solely on visually attractive books. ${ }^{22}$

Furthermore, Shawn Aubitz and Gail F. Stern stressed the importance of documents written in the first person, which "can offer intimacy and a sense of participation for the visitor and can explain or provide a context for an object." ${ }^{23}$ For example, a carbon copy of a typed 1965 letter by Dr. Eugene Stead expressing his intent to found what would become Duke's Physician Assistant Program-one of the first of its kind in the country-is a modest-looking document of great significance and power within the context of an exhibit celebrating the history of the program and the future of the profession. ${ }^{24}$ Additionally, a typed carbon copy may be of interest as an example of earlier technologies and modes of communication. While such materials may seem entirely ordinary to archivists, it is important to remember that they may not to visitors (an ever-increasing number of whom have never used a typewriter or seen an example of the document that gave its name to the "cc" field of an e-mail).

Using a combination of these document types in conjunction with other kinds of materials - three-dimensional objects, photographs, scrapbooks, and publications-created a diverse, visually compelling exhibit. For example, an exhibit on the institution's early founders included a newspaper clipping with a portrait of the first School of Medicine dean and founder of the hospital, Dr. Wilburt C. Davison; an early sketch he created of the hospital floor plan; a letter to Davison from the first School of Nursing dean, Bessie Baker, providing feedback on the hospital's organization; a 1960s patent for a medical device developed by Chair of Surgery Dr. J. Deryl Hart shown alongside an advertisement for the finished product; and a 1930s letter from Chair of Medicine Dr. Frederic Hanes to a Duke family member about the great potential of Duke Gardens. The newspaper article, sketch, patent, and advertisement had strong visual appeal, and the letters contained important information. Collectively, they created a striking and varied display with a strong narrative.

Exhibits also became an opportunity to showcase lesser-known and less used but interesting three-dimensional objects. Writing on the process of selecting materials for exhibitions, Deirdre Stam argued for reconsidering items that may fall outside of our normal purview:

although such exhibition material is sometimes peripheral to our own interests, we should recognize that curious and wonderful bindings, ephemera, realia, memorabilia, and book arts make for far more eye-catching exhibits than a more-or-less uniform series of run-of-the-mill printed pages. ${ }^{25}$

Again, the major challenge was identifying and prioritizing these items. Learning more about these materials was the first step and entailed pulling boxes from the artifacts collection to assess the contents, reviewing finding aids and searching the archives database to identify potentially relevant items from other collections, and taking note when encountering a possible item during processing or reference work. For example, 
while working with a box of hospital construction photographs and negatives for a reference request, an archivist came across a cloth napkin with an ink sketch of a plan for the new hospital that opened in 1980. She took a photo and made a note of it with the idea that the item could be used in a future exhibit about campus architecture or major milestones in the institution's history. Because of the visual nature of these materials, capturing information about them via a collection of images was more useful than a detailed spreadsheet. The image files were given names, including abbreviated information about each item's collection and location, and stored in an exhibits-related folder so they could be referred to later.

When assessing an item for display, the committee asked: What story (or stories) can this help tell? What can visitors learn from this? Using these kinds of questions as a guide, committee members incorporated a death mask into an exhibit about Duke Health founders; showcased a 1930s nursing cap, a midcentury doctor's bag, and 1970s employee patches in an exhibit about the history of health professionals' attire at Duke; and included an aircrew helmet with a flak hole, a case of medical instruments, and a morphine syrette in an exhibit about Duke's World War II medical unit. While these materials were not typically requested by researchers, within the context of an exhibit, they best communicated a unique and critical part of a narrative. The damaged flak helmet is an excellent example: it was worn by a patient treated at the unit, who, due to the work of the hospital staff, survived, despite serious injury. ${ }^{26}$ The object and its damage turned a potentially abstract, distant notion about the destruction of war and the treatment of patients into something tangible, specific, and memorable.

The committee also thought about how to develop exhibit topics and select materials relevant to the DUMCL\&A's demographic. As noted above, medical faculty and students can be a challenge to reach. Therefore, the committee strove to create exhibits that told specific stories, emphasized a sense of community and pride, and, when possible, spoke directly to student and faculty experiences at Duke, whether through early photographs of the building they work in, the backstory and institutional achievements that they might have read or heard about, or an image of the person whose statue they regularly pass on campus.

Through the process of installing the first few exhibits, committee members discovered that only a handful of items — typically six to eight—were needed per case. ${ }^{27}$ Furthermore, those who have written on the subject stress that a display featuring a few carefully selected, visually compelling items is more likely to draw visitors than a crowded case. ${ }^{28}$ This realization was powerful; having a clear idea of how many items an exhibit needs and recognizing that the cases need not be packed with endless examples made the process of identifying and selecting materials feel significantly easier and more manageable.

As others writing on exhibit planning have noted, seeking out partners also can provide additional options. ${ }^{29}$ The committee collaborated with Duke University's Rubenstein 


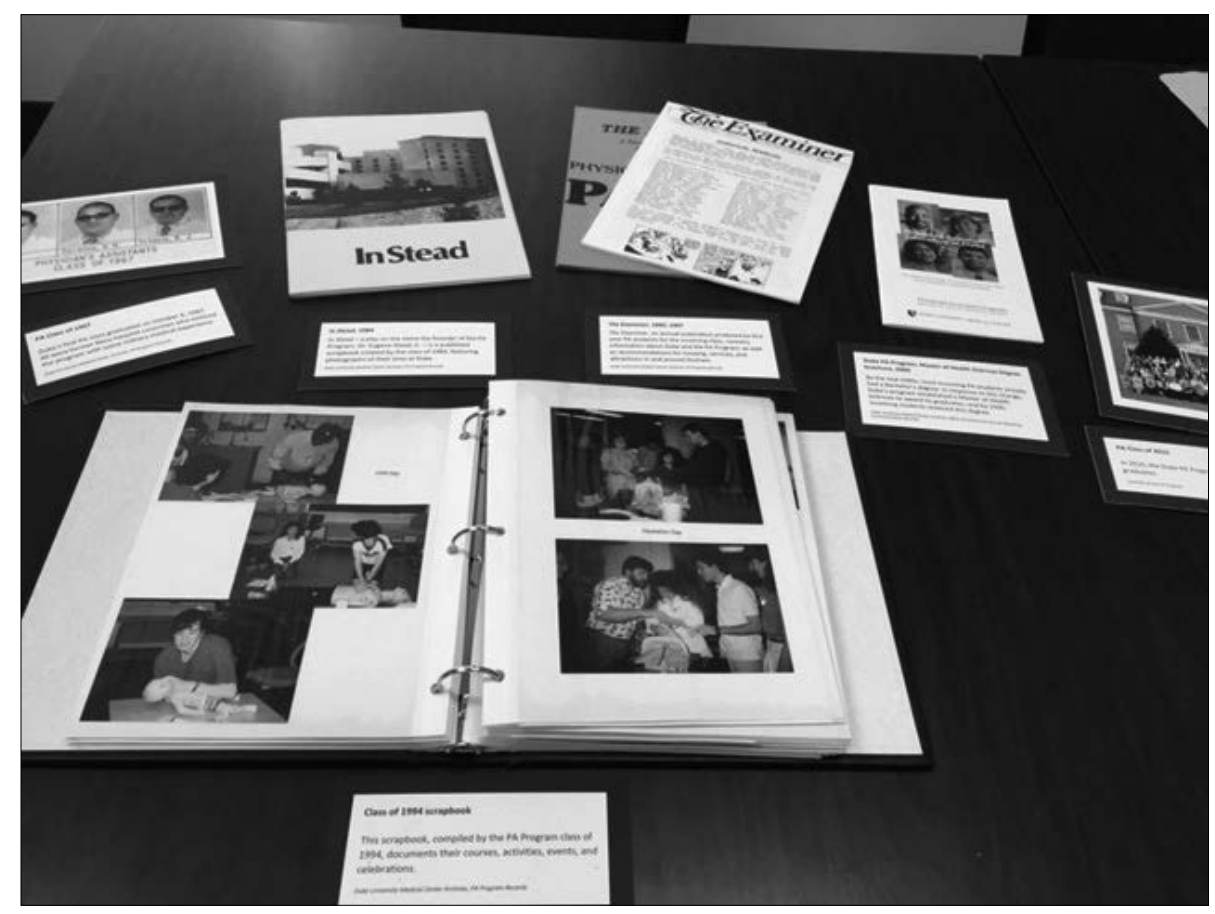

Typically only six to eight items were needed per case. This image shows the testing of a case layout.

Library on a Civil War medicine exhibit to run in conjunction with the DUMCL\&A's hosting of a National Library of Medicine banner display on African Americans in Civil War medicine. Committee members met with Rubenstein staff to discuss plans and select materials. The process was time intensive, but the partnership provided an opportunity to strengthen relationships with main campus librarians and reach a new audience. Alternately, working with smaller, local institutions can be an easier or quicker process than collaborating with larger organizations. For an exhibit celebrating Duke's Physician Assistant Program, the exhibits committee partnered with the Physician Assistant History Archives to borrow a stethoscope belonging to Dr. Eugene Stead, the program's founder. The process consisted of exchanging a few e-mails, completing loan paperwork, and arranging for delivery and return of the item.

Another option is to reach out to a relevant department, faculty person, or donor. ${ }^{30}$ For the Physician Assistant Program exhibit, the committee contacted the program's staff to obtain a high-resolution photograph of the current graduating class to feature alongside a 1967 image of the first graduates. When the division chief became aware of the exhibit, she offered to lend her copy of the 1966 Look magazine featuring an article about Duke's program. Even if an interaction does not result in acquiring materials for an exhibit, it can serve as an opportunity to let colleagues know about your work and to explore the potential for other kinds of collaboration. 


\section{Creating Exhibit Documentation}

During the first year, as the committee found itself remeasuring exhibit cases and continually discussing font size, the importance of documenting its decisions and process became increasingly clear. Creating documentation is one of the more straightforward parts of overseeing any major project, yet perhaps because it is so mundane, it can be easy to overlook. Too often, producing internal documents that improve workflow can get short shrift when archivists and librarians are accustomed to prioritizing patrons' needs and creating products for an audience. However, if, as Catherine Nicholls contended, "the literature highlights the ad-hoc nature of activities such as exhibitions in many archive programmes and suggests that such an ad-hoc approach is a key factor in activities being inefficient or unsuccessful," documentation can play a pivotal role in codifying and legitimizing a program. ${ }^{31}$ Furthermore, outlining a program's goals, scope, standards, and procedures can provide a clear blueprint that enables staff to keep track of work, save time, communicate more effectively, identify areas for improvement, and help articulate its value to the parent institution. ${ }^{32}$

Research and experience were equally essential for creating the program's documentation. As noted above, reading informed the committee's ideas about key aspects of exhibit planning, such as the content and look of exhibit labels. But the committee also had to complete a couple of exhibits to gain a sense of the process first-hand to, for example, create a timeline. The exhibit policies and procedures document was a 12-page guide that provided an overview of the planning and installation process. It included goals and criteria, a planning schedule, a timeline, approved materials, guidelines for writing labels, and basic procedures for installation..$^{33}$ For a committee of five, this document was essential to ensuring consistency. Moreover, as the components to installing an exhibit were too numerous to remember, the document served as a quick way to verify information, whether label format, the location of supplies, or what needed to be done four weeks before installation. It also proved useful for explaining the program to others. When an archives intern expressed an interest in working on exhibits, sharing this document saved staff time and provided her with a clear overview of the process.

An important step in creating this document and establishing the program was determining the goals and criteria. The committee agreed that exhibits are an important component of a vital outreach program, key for promoting collections and furthering the library's educational mission, and a means of raising the visibility of the archives and its unique materials. ${ }^{34}$ The committee also consulted the goals outlined in the DUMCL\&A's strategic plan to ensure that the exhibit program goals would align and, as noted above, reviewed the documentation of other institutions for examples. Deciding on and articulating the goals and criteria were essential, as they provided a rubric for generating and assessing potential exhibit topics. ${ }^{35}$

In addition to the policies and procedures guide, the creation of other supplementary documents helped to plan and monitor work. An exhibit inventory was a spreadsheet with information about and a description of each exhibit item, the collection it came 
from, its stacks location, its size, and whether the original item or a copy was to be used in the display. This simple but crucial document allowed committee members to physically and intellectually keep track of materials. Adapted from a Duke University Libraries document, the publicity contacts checklist enabled the committee to track who should receive exhibit announcements. This spreadsheet was divided into a several sections: internal promotion, contacts throughout the Medical Center, contacts on the main university campus, local community contacts, and archives and library community contacts. Each unit or organization included a contact name, title, and information. ${ }^{36}$ Like the exhibit inventory, this document was a basic but effective means of maintaining control over this part of the process.

Last, the committee created an exhibit schedule. For the first several months of its existence, the committee worked from exhibit to exhibit without a long-term plan. Topics were generated as needed, selected based on members' interests, and chosen without any prior research to determine if the collections held a strong selection of relevant materials. Recognizing that this was not ideal, members agreed to give some thought to possible topics and then met to brainstorm and discuss. During this meeting, the committee generated several ideas, ranked them, and slotted them into a calendar with the idea that one of the archivists would review collections to ensure that these were viable exhibit topics. The committee also tried, as Joan Rabins suggested, alternating between more time-intensive exhibits and those easier to execute. ${ }^{37}$ Having a schedule for more than a year in advance provided a clear plan and peace of mind. Furthermore, it gave the archivists on the committee a greater opportunity to work in advance. If during their daily work they came across an item that might have potential for an upcoming exhibit, they were able to flag it and record the information, meaning that when the committee began work on a topic, some potential items had already been identified.

\section{Conclusion}

Exhibit work is a complex undertaking, and the DUMCL\&A's exhibit committee did not explore every possible component of the process. For example, it did not pursue assessing the visitor's experience. ${ }^{38}$ Instead, the committee's work focused on three of the biggest challenges of creating an exhibits program at a small library or archives: learning how to create exhibits, identifying and selecting materials, and determining and documenting policies and procedures.

Over the course of creating several exhibits, the committee learned some important lessons. One was to resist the pursuit of perfection, which can drain time, energy, and resources. While it may be tempting to fixate on details, it is useful to remember that most visitors will not have the same expertise or personal investment in the topic and will not subject the exhibit to the level of scrutiny that those curating it do. Instead, work efficiently and aim for continual improvement. Setting clear parameters and time limits early on can help prevent exhibit planning and preparation from encroaching on other projects and deadlines. 
Another major lesson the committee learned was that less is more. This is true for the amount of material needed to create attractive cases, for writing labels, and for the number of exhibits scheduled in a year. (For example, the committee began with four exhibits annually, but later scaled back to three.) In the beginning, the committee often overestimated what needed to be done and what could be comfortably accomplished. As members reflected on their first year, they realized that the process would have been easier if they had started with smaller, more easily achievable goals and built in extra time for complications or delays.

Reading the literature and reviewing the documentation of other institutions-combined with the experience of curating and installing exhibits-was crucial to the development of the exhibit committee's knowledge and confidence as well as to determining and documenting policies and procedures. This process was not fast, but within a year came tangible results. For example, the exhibit committee took photos of each completed exhibit for recordkeeping. When comparing images of the earliest exhibits with those completed a year after establishing the program, the improvement in selection and display of materials, standardization, and storytelling could be seen clearly.

Although initially concerned about the archives' limited holdings, the committee found that there were materials worth showcasing. It simply needed to take a proactive approach to learning about the collections with new criteria in mind and to think strategically about how to select, organize, and display items. Allowing collection strengths to guide exhibit topics and developing topics well in advance were both key in helping the committee locate materials that could tell a compelling and visually dynamic story. Somewhat unexpectedly, exhibits also became an opportunity for internal promotion of the archives' collections. The committee received informal feedback from colleagues surprised or excited to discover materials in an exhibit that they did not realize were part of the DUMCL\&A's collections.

Finally, the committee found that creating documentation saved time, made the process go more smoothly, and improved the quality of the exhibits. For example, deciding on and standardizing the font and text size for exhibit labels may seem like a relatively small piece of the process, but having this in place meant that it did not need to be continually revisited for each exhibit. Additionally, it also meant that even if more than one committee member worked on labels, the content produced still had a consistent appearance. Despite the committee's limited experience and resources, through practice, consulting the literature, and creating documentation, it was able to create a successful exhibits program. 


\section{ABOUT THE AUTHOR}

Jolie Braun is the curator of American literature at The Ohio State University, where she collaborates with faculty to provide special collections-based learning opportunities for students and actively builds the American literature collection. Previously, she was the assistant director at the Duke University Medical Center Archives, where she helped establish the exhibits program.

\section{NOTES}

1. An early version of this paper was presented at the 2015 Society of Tennessee Archivists Conference. I would like to thank Eric Johnson, Jennifer Schnabel, Tamar Chute, Michael Daines, and the Archival Issues editor and peer reviewers for their feedback on this paper.

2. The aim of the exhibits committee most directly corresponded with one of the items in the DUMCL\&A vision statement from this period: "Collecting, preserving, and providing access to Duke's records and history."

3. The total cost per exhibit was always less than $\$ 100$.

4. Mary E. Brown and Rebecca Power, Exhibits in Libraries: A Practical Guide (Jefferson, NC: McFarland \& Company, 2006), 7.

5. Jessica Lacher-Feldman, "Creating the Curator: Teaching and Learning Exhibit Development for Special Collections, Librarians and Archivists," Exbibitionist (2014): 54.

6. Jessica Lacher-Feldman, Exhibits in Archives and Special Collections (Chicago: Society of American Archivists, 2013).

7. Beverly Serrell, Exbibit Labels: An Interpretative Approach (Walnut Creek, CA: Altamira Press, 1996).

8. The Library at the University of Illinois at Urbana-Champaign's "Library Exhibition Bibliography" is an excellent starting place for resources on the topic, http://www.library.illinois.edu/committee/ exhibit/ExhibitionBibliography.html.

9. Jennifer Brannock. "Creating an Exhibit in Special Collections and Using It to Promote Collections and Educate Users," Mississippi Libraries 73 (2009): 32-34.

10. Stephen Bitgood, "Practical Guidelines for Developing Interpretive Labels," Visitor Behavior 11 (1996): 4-7.

11. Stephen Bitgood, “The ABCs of Label Design,” Visitor Studies 1 (1991): 115.

12. National Library of Scotland and the University of Edinburgh, "Exhibiting the Written Word," http://www.ed.ac.uk/literatures-languages-cultures/english-literature/research/recent/exhibitingwritten-word.

13. At present, ACRL/RBMS provides documentation on exhibition loan policies but not exhibition policies. However, the ARL publication Special Collections Engagement (2010) includes a selection of exhibit policy documents, http://publications.arl.org/Special-Collections-Engagement-SPECKit-317.

14. Examples include the Northeast Document Conservation Center's Preservation Leaflets, most notably "2.5 Protecting Paper and Book Collections during Exhibit," by Mary Todd Glaser; "A Set of Conservation Guidelines for Exhibitions," by Toby Raphael and Martin Burke, which may be accessed through CoOL, Conservation Online (http://cool.conservation-us.org); and the National Information Standards Organization's "Environmental Conditions for Exhibiting Library and Archival Materials."

15. For those interested in such opportunities, the exhibit committee recommends reaching out to your local or regional organization, as they often look to member needs and priorities when planning 
educational programming. Additionally, Jessica Lacher-Feldman has taught an SAA course on exhibitions, http://www2.archivists.org/prof-education/course-catalog/archival-exhibitions.

16. Brannock, "Creating an Exhibit in Special Collections and Using It to Promote Collections and Educate Users," 33.

17. Albert H. Leisinger Jr., "The Exhibit of Documents," The American Archivist 26, no. 1 (1963): 75-86.

18. Jane Kemp, "Creating Exhibits in the Smaller Academic Library," College E Research Libraries Nerws 7 (July 1985): 344-46

19. "About the Duke Medical Center Library and Archives," Duke University Medical Center Archives, https://mclibrary.duke.edu/about.

20. “Departmental History,” Duke University Medical Center Archives, https://archives.mc.duke.edu/ departmental-history.

21. Nancy Allyn, Shawn Aubitz, and Gail F. Stern, "Using Archival Materials Effectively in Museum Exhibitions," The American Archivist 50, no. 3 (1987): 402.

22. National Library of Scotland and the University of Edinburgh, "Exhibiting the Written Word."

23. Shawn Aubitz and Gail F. Stern, "Developing Archival Exhibitions," MARAC Technical Leaflet, no. 5 (1990): 2 .

24. “Eugene A. Stead, Jr., MD,” Physician Assistant History Society, http://www.pahx.org/stead-jreugene.

25. Deirdre Stam, "Bridge That Gap! Education and Special Collections," RBM: A Journal of Rare Books, Manuscripts, and Cultural Heritage 7, no. 1 (2006): 22.

26. Some of the most common and serious injuries suffered by patients treated at the hospital were due to flak, the enemy anti-aircraft fire that often sent varying-sized shell fragments tearing through planes and wounding men. More on this topic is available at "Remembering the 65th: Duke's General Hospital Unit," https://digitaldukemed.mc.duke.edu/sixty-fifth.

27. For reference, the exhibit space consisted of two flat cases that were 56 inches wide and 22 inches deep, and two tall cases 40 inches wide and 48 inches tall.

28. Joan Rabins, “Archival Exhibits: Considerations and Caveats," Georgia Archive 8, no. 2 (1980): 34; William F. Schmidt, "The Rotating Case Display: An Opportunity," The American Archivist 28, no. 4 (1965): 521-25.

29. Susan Brazer and Andrea Wyman, "Display Cases for Academic Libraries: Ten Tips for Display Case Persons," College and Research Libraries News 62 (2001): 904-8; Jane Kemp, "Creating Exhibits in the Smaller Academic Library," College E Research Libraries Nerws 7 (1985): 344-46.

30. Ibid.

31. Catherine Nicholls, "Exhibiting Evidence: A Case Study," Archivaria 55 (2003): 30.

32. Lacher-Feldman, Exbibits in Archives and Special Collections Libraries.

33. The DUMCL\&A's exhibit planning timeline has been included as an appendix.

34. Lesley Brown, "Acquiring Literacy: A Library Exhibit," RBM: A Journal of Rare Books, Manuscripts, and Cultural Heritage 14, no. 2 (2013): 82-91; Rabins, "Archival Exhibits," 29-40.

35. The DUMCL\&A's exhibit goals and criteria have been included as an appendix.

36. For example, the internal promotion section includes several different pieces: the DUMCL\&A website homepage, blog, newsletter, Facebook page, digital signage, and an all-staff e-mail.

37. Rabins, "Archival Exhibits," 29-40.

38. For case studies of exhibit assessment, see Auten et al., "Using NLM Exhibits and Events to Engage Library Users and Reach the Community," Medical Reference Services Quarterly 32, no. 3 (2013): 266-89; and Nicholls's "Exhibiting Evidence." Both provide useful discussions of evaluating exhibit success and visitor satisfaction. 


\section{APPENDIX A}

The following timeline, excerpted from the DUMCL\&A's policies and procedures document, works well for planning an exhibit comprised of four cases.

\section{Exhibit Planning Timeline}

- On an annual basis:

- Review and approve exhibit schedule as a group

- Identify possible partnerships for upcoming exhibits. (If Rubenstein participates, contact at least 1 year in advance, and follow up within 6 months.)

\section{2 weeks before exhibit opens:}

- Send out call for volunteers from exhibit committee; determine who will participate and how they will contribute

- Determine if outside assistance or support will be needed, and identify groups or individuals to reach out to; contact as soon as possible

- If appropriate, begin to arrange loans from other departments

- Select days and times for installation and de-installation

- Begin researching topic and taking notes

- Begin identifying possible materials to include; review images and notes in Exhibits folder for options

- Review publicity checklist to see who should be contacted about exhibit

\section{8 weeks:}

- Develop a narrative: determine the themes of each case and decide on an exhibit name

- Scan any images that will be included

- Begin an inventory of items that will be included

- Consult the preservation staff on main campus if there are any questions or concerns about exhibiting particular items

- Review materials selected to include and make final decisions, determine if any additional items are needed

- Write exhibit labels

- Consider the size of the materials being used; measure items to ensure a good fit

\section{4 weeks:}

- Gather all materials and test layout each case

- Review and finish writing labels

- Proofread all labels; have at least one other committee member review

- Design banner and poster 
2 weeks:

- Send any graphics (banners, poster, etc.) that need to be printed to FedEx Kinko's

- Send labels to be printed to FedEx Kinko's

- Print out, cut to size, and mount all scanned images

\section{Week of Installation:}

- Promote exhibit using publicity checklist as guide

\section{APPENDIX B}

The following goals and criteria, excerpted from the DUMCL\&A's policies and procedures document, help the exhibits committee articulate its mission and focus, and develop and evaluate potential exhibit topics.

\section{Goals}

- Present an engaging and informative exhibit relevant to the target audience

- Highlight collections and materials

- Educate the community on the history of medicine and Duke Health topics

- Recognize significant accomplishments, individuals, and stories at Duke Health

- Promote the role of the Library and Archives

\section{Criteria}

- Appropriateness and appeal of subject

- Relevance to collections

- Relevance to special events, anniversaries, etc.

- Relation to other events or exhibits at the institution or in the local community 